\title{
METHODS FOR IDENTIFICATION AND VISUALIZATION OF MUNICIPAL WASTE DISPOSAL SITES USING AEROSPACE DATA
}

\author{
Adlin Dancheva
}

\begin{abstract}
With the increase of temperatures in the summer, the danger of self-ignition of landfills for household waste increases, because of the biochemical processes that take place inside them. The most recent example is the municipal landfill for non-hazardous waste near the town of Dupnitsa. The self-ignition started on July 23, 2021 and continued to smolder for almost a week, which led to a great danger of burning the area around it or poisoning the population. It is believed that one of the main reasons is the great depth of the accumulated waste. There is an urgent need to do quality control of most of the landfills for municipal waste in our country. Some of them are located next to major river arteries or international roads. Non-compliance with the requirements for maintenance, management and operation hides a serious potential for an ecological catastrophe. It is essential that stricter measures are taken and that these landfills are monitored. The aim of the present work is to reveal the possibilities and potential of aerospace data and to show different methods for processing, interpretation, and visualization. They can easily identify, map, and survey a waste disposal site. Optical images of the multispectral instrument (MSI) of the Sentinel 2 platform and radar (SAR) data from the Sentinel 1 platform of the Copernicus program of the European Space Agency were used. Thermal bands from the Landsat 5 - 7 (ETM) and Landsat 8 (OLI/TIRS) sensors of the Landsat program were used to calculate the land surface temperature. Satellite images have been orthogonized, and composite images between optical and radar data have been created for better visualization.
\end{abstract}

Keywords: Land surface temperature, landfills, monitoring, aerospace data

\section{INTRODUCTION}

The studied object in the present work is a regional landfill for household waste in Burgas. It is located near the village of Bratovo and Vaya Ecopark. It was opened in 1982 and closed in 2015. Reclamation activities are currently underway on the territory of the landfill. They will take place in two stages. The first type of treatment involves shaping the landfill cell, re-depositing waste, cleaning the surrounding areas and draining the contaminated water. A construction of facilities for the removal of the biogas contained in the deposited materials is forthcoming. Biological reclamation includes soil placement and grass planting, which will allow the site to become a natural part of the surrounding environment. The reclamation of the landfill for non-hazardous household waste aims to prevent environmental pollution, as well as to prevent the penetration of surface water into the waste cell.

Fig. 1 represents the location of waste disposal sites (WDS) of Burgas, Bulgaria.

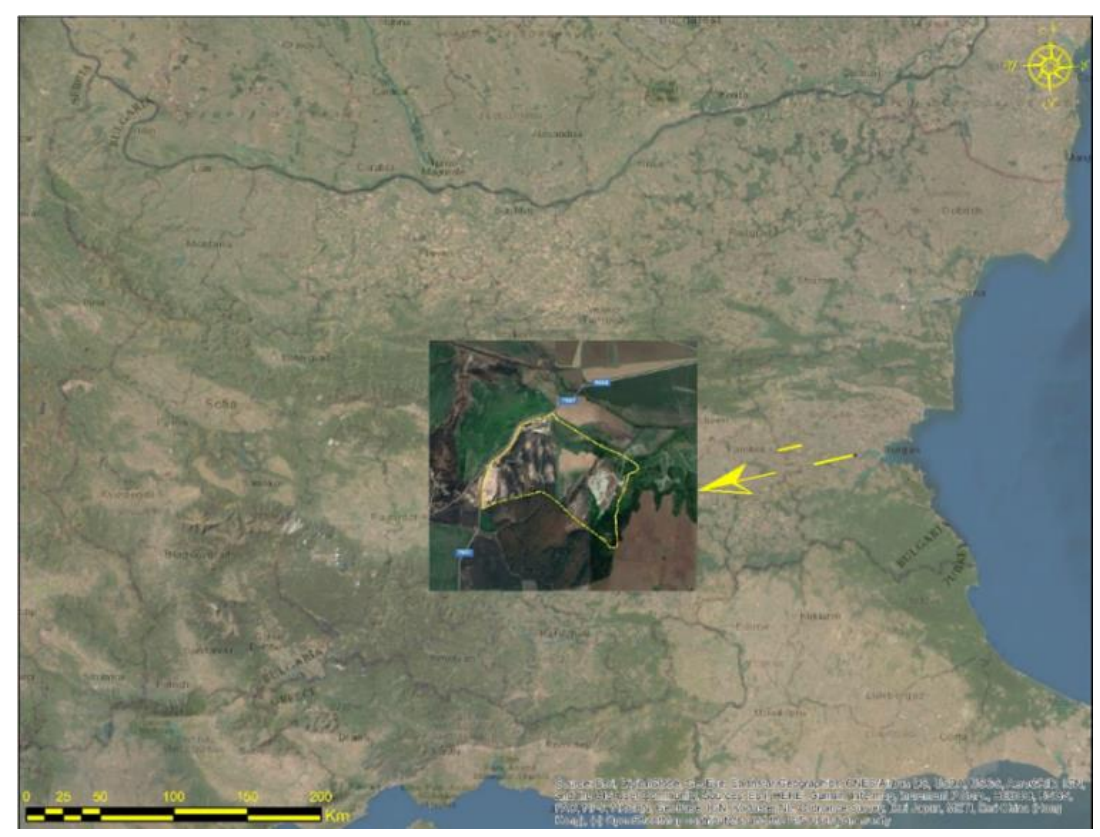

Fig. 1. Location of WDS Burgas 


\section{MATERIALS AND METHODS}

This survey methodology is based on the use of satellite data that examines bands on the thematic infrared sensors (TIRS). From this data, information is extracted about the actual heat emission of waste disposal sites, which is related to the land surface temperature of the surveyed sites. The landfill temperature is calculated using the digital number (DN) contained in the TIRS. In this case, data from the Landsat 5 (ETM) sensors is most appropriate, using the band 6 with wavelength range $10.40-12.50$ $\mu \mathrm{m}$ and for Landsat 8 (OLI/TIRS) band 10 with wavelength range $10.6-11.19 \mu \mathrm{m}[1,2]$ for calculation of the endemic heat radiation from the landfill. The selected images are from different years and different seasons. The multispectral instrument (MSI) Sentinel 2 sensor data is used for the spectral characteristics. The same data was also used for Tasseled cap transformation (TCT) and this is the most commonly used landfills recognition method. This approach was chosen because it is possible to interpret, classify and analyze phenomena and processes related to the dynamics and change of the basic components of the earth's surface - moisture, soil and vegetation $[3,4]$. For better visualization of the landfills, a combination of radar and optical images from Sentinel 1 and Sentinel 2 were used [5].

Table 1. Satellite data

\begin{tabular}{|llll|}
\hline Date & Satellite & Date & Satellite \\
\hline $\mathbf{1 9 . 0 6 . 2 0 1 3}$ & Landsat 8 OLI & $\mathbf{1 2 . 0 8 . 2 0 1 9}$ & Landsat 8 OLI \\
\hline $\mathbf{2 7 . 0 7 . 2 0 1 5}$ & Landsat 8 OLI & $\mathbf{0 5 . 0 8 . 2 0 2 1}$ & Sentinel 2 MSI \\
\hline $\mathbf{0 7 . 0 8 . 2 0 1 9}$ & Landsat 8 OLI & $\mathbf{1 4 . 0 8 . 2 0 2 1}$ & Sentinel 1 (SAR) \\
\hline $\mathbf{1 0 . 1 0 . 2 0 1 9}$ & Landsat 8 OLI & & \\
\hline
\end{tabular}

We can use a general formula for Landsat 4-8:

$\mathrm{T}_{[K]}=\mathrm{a} * \ln ^{-1}\left(\frac{b}{c * Q+d}+1\right)$,

where: $a, b, c$, and $d$ are the constants for the different types of Landsat images, $\mathrm{T}$ is the pixel temperature $(\mathrm{K})$; $\mathrm{Q}$ is the spectral brightness coefficient of the surface in the thermal channel. Landsat $5-7$ (ETM) and Landsat 8 (OLI/TIRS) satellites' images are downloaded from web page https://earthexplorer.usgs.gov/ [6].

After the georeferencing procedure of the thermal images the cutting out of the rectangular sections in each image covering the vicinity of the geographic coordinates is carried out. The time series $\{\mathrm{Q} 1, \mathrm{Q} 2$, . $\ldots, Q n\}$ of the images in the thermal channel of each WDS are extracted. The data from the image is converted into the surface temperature $\{\mathrm{T} 1, \mathrm{~T} 2, \ldots$, $\mathrm{Tn}$ \} using transformation:

$$
\mathrm{T}_{\left[{ }^{\circ} \mathrm{C}\right]}=\mathrm{a} * \ln ^{-1}\left(\frac{b}{c * Q+d}+1\right)-273.15,
$$

where: a is the $K_{2}=$ Thermal conversion constant for the band (K2_CONSTANT_BAND_n from the metadata); $\mathrm{b}$ is $K_{1}=$ Thermal conversion constant for the band (K1_CONSTANT_BAND_n from the metadata); $\mathrm{c}$ is $M_{l}=$ Radiance multiplicative scaling factor for the band (RADIANCE_MULT_BAND_n from the metadata); $\mathrm{d}$ is $L_{\lambda}=$ Spectral radiance $(W /$ $(m 2 * s r * \mu m)) ; \mathrm{Q}=\mathrm{L} 1$ pixel value in $\mathrm{DN} ; \mathrm{T}=\mathrm{TOA}$ (Top of Atmosphere) Brightness Temperature.

The time series for WDS are formed together with the mask for clouds and "blankness" and are entered into the database. The time series of images for temperature for each landfill or WDS is systematized.

\section{RESULTS AND DISCUSSION}

A tasseled cap transformation has been made to identify landfills from the individual elements of the earth's surface. A merge was made between optical and SAR images. For better visualization, a composite image of SAR and optical data has been made. 


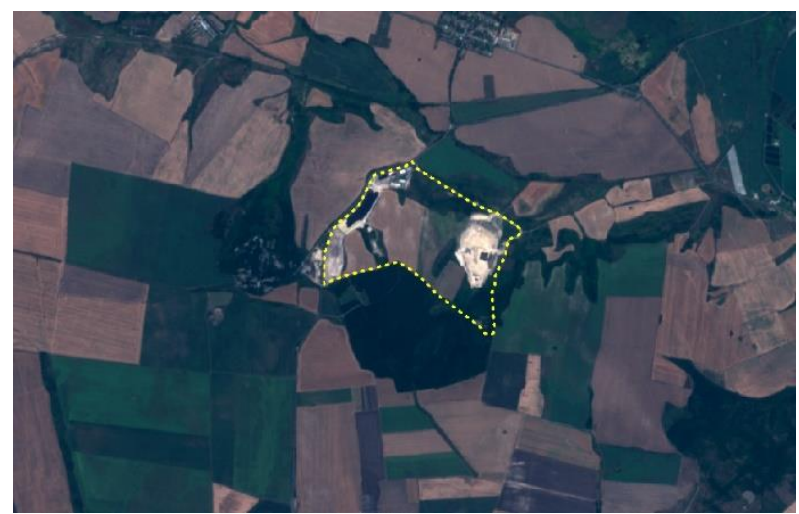

Fig.2. Composite image from Sentinel 2; bands: 4-3-2

Fig. 2 shows a composite image of the multispectral instrument of Sentinel 2 in the visible spectrum with bands 4-3-2. Fig. 3 shows a composite image of Sentinel 2 in a composition with channels 12-8-4. This composition represents the primary method for recognizing a landfill. The colors inside

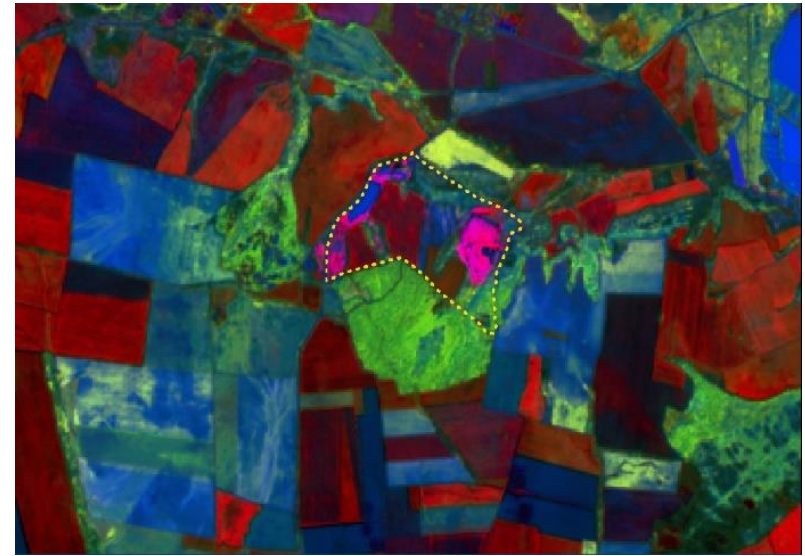

Fig. 4. Orthogonal transformation (TCT) - Sentinel 2

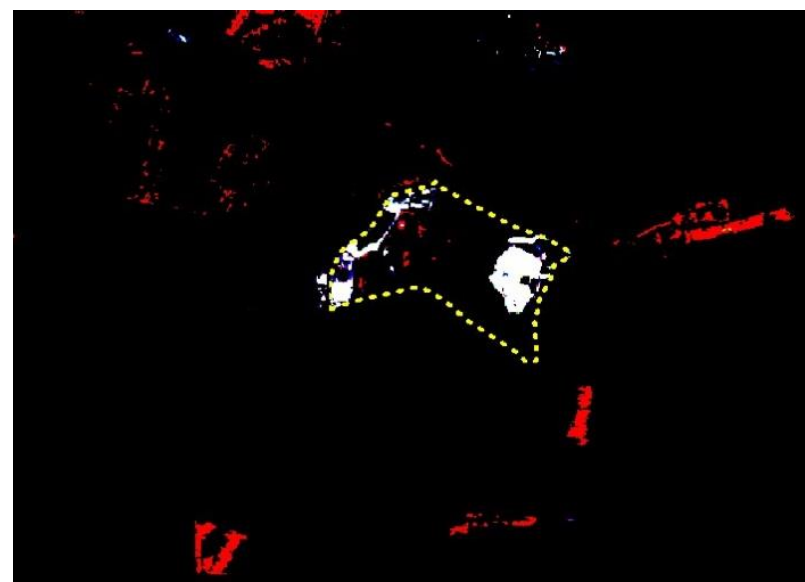

Fig. 6. Composite image of optical data in density slicing

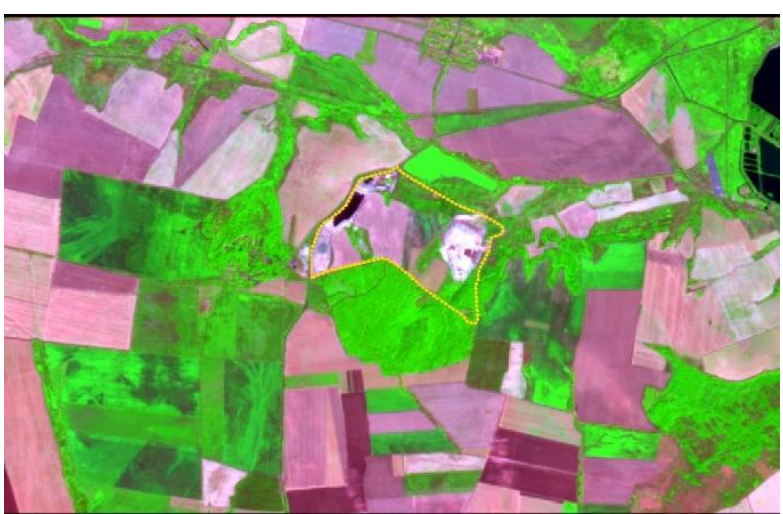

Fig. 3. Composite image from Sentinel 2; bands: 12-8-4

the boundaries of the landfill differ from the rest of the surface [5].

Fig. 4 shows the orthogonal transformation (tasseled cap transformation) of the studied object. The landfill is colored purple and clearly stands out from the rest of the surface.

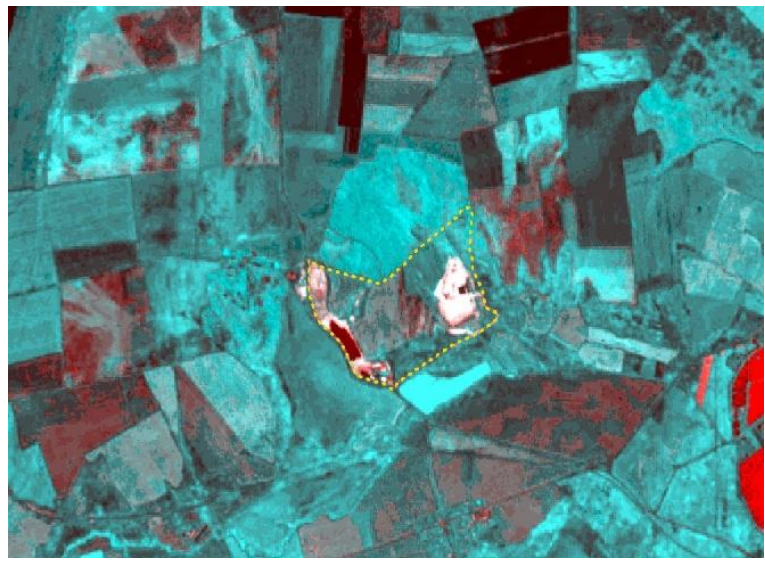

Fig. 5. Merge between SAR and TCT

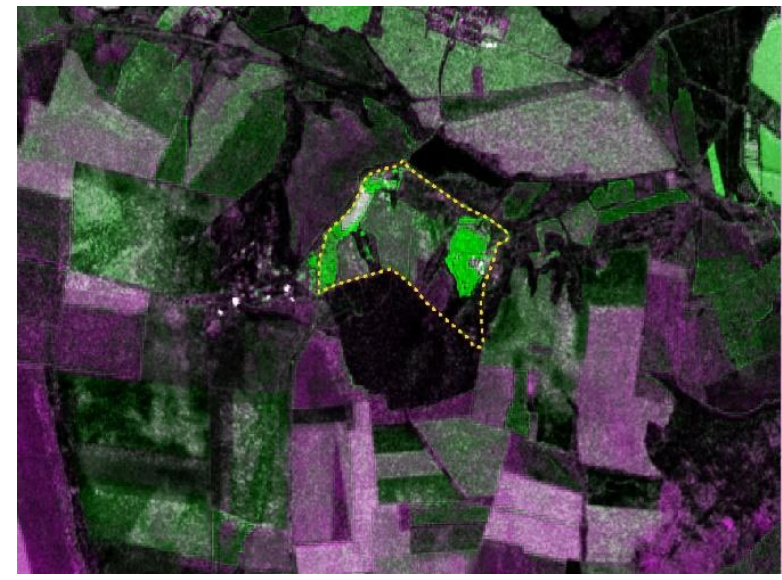

Fig. 7. Composite image of SAR with VV polarization and spectral band $4-$ Sentinel 2 
Density/Level slicing was used to highlight the differences in pixel values and to distinguish the waste disposal site from the rest of the surface (Fig. 6). Fig. 7 shows a composite image from data of MSI and SAR with bands: 13 (VV polarization), $4^{\text {th }}$ band of MSI image and band 13 (VV polarization). And with this method of visualization, the landfill in Burgas stands out and differs from the rest of the surface.

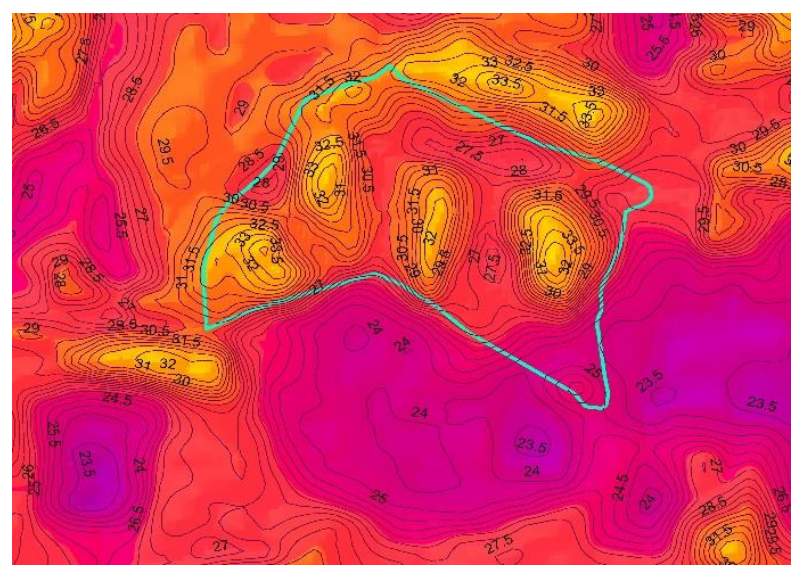

Fig. 8. LST of WDS Burgas -19.06.2013

\section{CONCLUSION}

Various methods for visualization and interpretation of satellite data have been developed for the purpose of studying landfills for municipal waste. A combination of radar and optics was used. Thanks to the satellite data, a qualitative and quantitative assessment can be made for the study of a site, as well as monitoring of a landfill for municipal waste, thus it is possible to monitor thermal pollution and take measures to stop its spread.

\section{REFERENCES}

1. Dancheva, A. and S. Asenovski, Study of waste disposal thermal radiation using satellite data and considering solar influence, Aerospace Research in Bulgaria. 30, (2018).

2. Richter, A., M. Kazaryan, M. Shakhramanyan, R. Nedkov, D. Borisova, N. Stankova, I. Ivanova, and M. Zaharinova, Quality enhancement of satellite images and its application for identification of surroundings of waste disposal sites, Proc. SPIE 10444, 104441N-1-7 (2017).

3. Nedkov R., Orthogonal transformation of segmented images from the satellite Sentinel-2," Comptes rendus de l'Académie bulgare des sciences, 70(5), 687-692 (2017).
Fig. 8 shows the land surface temperature (LST) of the landfill in Burgas district from 19.06.2013. There is an increase in temperature on the northern side of the landfill border and inside the border reach $+33.5^{\circ} \mathrm{C}$, which is significantly higher than the ambient temperature. Fig. 9 shows a temperature spill on the east side leaving the landfill boundary. The highest temperature that is measured is $+37^{\circ} \mathrm{C}$.

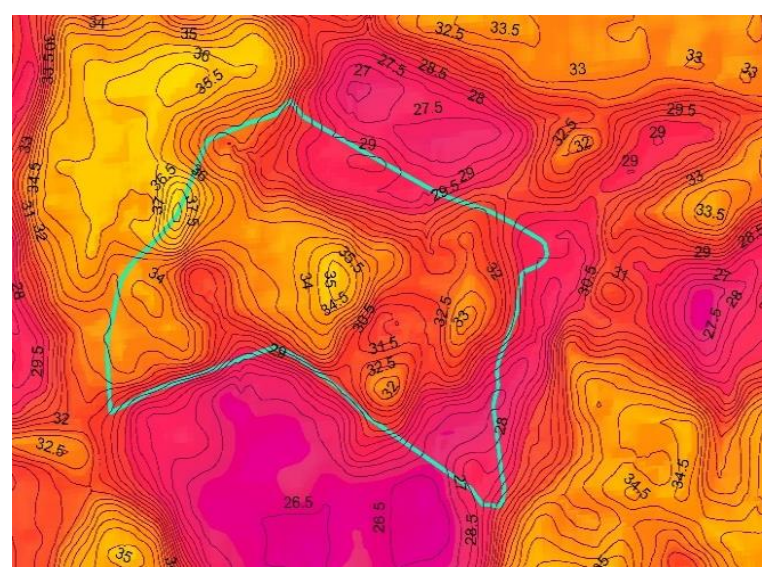

Fig. 9. LST of WDS Burgas - 12.08.2021

4. Stankova, N., R. Nedkov, I. Ivanova, D. Avetisyan, Modeling of forest ecosystems recovery after fire based on orthogonalization of multispectral satellite data. Proc. SPIE 10790, Earth Resources and Environmental Remote Sensing/GIS Applications IX, 10790, SPIE, (2018), DOI:10.1117/ 12.2325643

5. Dancheva, A. Differential estimation of temperature changes in landfills through the use of satellite data, Proc. SPIE 11534, Earth Resources and Environmental Remote Sensing/GIS Applications XI, 115340J (20 Sept. 2020). https://doi.org/ 10.1117/ 12.2574057

6. https://earthexplorer.usgs.gov/

7. Kuenzer, C. et al. Spaceborne thermal infrared observation - an overview of most frequently used sensors for applied research, in: Kuenzer, C. and S., Dech, (eds) Thermal Infrared Remote Sensing SE-7. Springer Netherlands (Remote Sensing and Digital Image Processing), 131-148. DOI:10.1007/978-94007-6639-6_7

8. Landsat 8 Data Users Handbook, (2016), v.2. USGS, https://landsat.usgs.gov/sites/default/files/ documents/Landsat8DataUsersHandbook.pdf

9. Richter, A., M. Kazaryan, M. Shakhramanyan, R. Nedkov, D. Borisova, N. Stankova, I. Ivanova, and M. Zaharinova, Estimation of thermal characteristics of Waste disposal sites using Landsat satellite images, 
Comptes rendus de l'Academie bulgare des Sciences, 70(2), (2017).

10. Nedkov, R., Quantitative assessment of forest degradation after fire using ortogonalized satellite images from Sentinel-2, Comptes rendus de l'Academie bulgare des Sciences, 71(1), 83-86, (2018).

\section{Adlin Dancheva}

Space research and technology institute - BAS 1, Acad. G.Bonchev Str.

Sofia 1113, Bulgaria

e-mail: adlin.dancheva@space.bas.bg
11. Dancheva, A., R. Nedkov, T. Spasova, D. Borisova, N. Georgiev, Using optical and radar images to study the thermal pollution from the waste disposal site around Vidin area, Proc. SPIE 11149, Remote Sensing for Agriculture, Ecosystems, and Hydrology XXI; 1114928, (2019), https://doi.org/ $10.1117 / 12.2538116$

\author{
Адлин Данчева \\ Институт за космически изследвания и \\ технологии - БАН \\ ул. „Акад. Георги Бончев“, бл 1 \\ София 1113 \\ e-mail: adlin.dancheva@space.bas.bg
}

